\title{
Price convergence of peripheral European countries on the way to the EMU: A time series approach*
}

\author{
Miriam Camarero $^{1,2}$, Vicente Esteve ${ }^{3}$, Cecilio Tamarit ${ }^{2,3}$ \\ ${ }^{1}$ Departamento de Economía, Campus del Riu Sec, Jaume I University, E-12080 Castellón, Spain \\ ${ }^{2}$ Wharton School, University of Pennsylvania, Philadelphia, PA 19104, USA \\ ${ }^{3}$ Facultad de Ciencas Económicas y Empresariales, Departamento de Economía Aplicada II, \\ Universidad de Valencia, Apartado Oficial 22006, E-46071 Valencia, Spain \\ (e-mail: cecilio.tamarit@uv.es)
}

First version received: March 1997/final version received: May 1999

\begin{abstract}
This paper examines price and inflation convergence between three European countries (Italy, Spain and the U.K.) and a European average and, alternatively, between them and Germany from the beginning of the 80's.

For this purpose the long-run stochastic relationships on prices derived from the convergence criteria agreed in the Maastricht Treaty are analyzed. In order to do this, some recent unit root tests have been applied as well as timevarying parameters models.

The results reject the long-run convergence hypothesis in all the cases but allow us to accept the existence of catching-up with the European average and Germany in some cases depending on the nature of the prices and on the countries considered.
\end{abstract}

Key words: Nominal convergence, unit root, cointegration, time-varying parameters

JEL classifications: C22, E31, F15

\section{Introduction}

After the Maastricht Treaty in 1991, economic convergence among European Union (EU) member states became a condition to be fulfilled before the

\footnotetext{
* The authors gratefully acknowledge the financial support of the projects CICYT-PB94-0955CO2-01 and 02, DGICYT-PR95-206 (M. Camarero) and DGICYT-PR95-213 (C. Tamarit). They are also indebted to Pierre Perron who provided the empirical procedures for unit root tests. This paper has benefited from comments by Richard Marston, Frank Diebold and an anonymous referee, as well as the participants at the Wharton School Finance Department Lunch Seminar and the Econometric Society European Meeting (ESEM-96) in Istanbul. The usual caveat applies.

All correspondence to C. Tamarit.
} 
achievement of the Monetary Union. Whatever strategy one considers, economic convergence seems to be at the core of the debate concerning Economic and Monetary Union in Europe (EMU). From the so-called "economist" point of view, convergence among member countries is a prior requirement before moving towards EMU. Similarly, according to the "monetarist" approach, convergence must also be studied in light of the European Monetary System (EMS) experience in order to assess potential benefits from EMU.

Therefore our aim in this paper is to test whether the presence of the EMS has favored a process of price convergence between three peripheral European countries (namely Italy, Spain and the UK) and Germany, or at least between them and an average of the countries taking part in the EMS. Once the choice of the countries entering in the first wave of EMU has been made, and finally a "large" monetary union will start working in 1999, the results of this paper can be useful to provide some insights for the future performance of EMU (in the case of Spain and Italy) and its relation with pre-ins countries (namely U.K.).

At the time when the EMS was established, the most important difference in macroeconomic performance across Europe was in the inflation rates levels. Figures 1 and 2 show the behavior of the inflation rates in Spain, the U.K. and Italy compared to Germany and the EMS using consumer price indexes (CPI) and industrial output prices (IOP), respectively. In 1981, CPI inflation was around 5 percent in Germany and 9 percent on average in the rest of Europe, with peaks of 19 percent in Italy, 14 percent in Spain and 12 percent in the UK. However, in the 1980s European inflation rates seemed to converge fast, narrowing the inflation differential with Germany. At this point, the question is to know if convergence has already been achieved by these countries or, if at least, they are in process of convergence.

The present research is related to a growing amount of empirical literature on the role of the EMS in achieving convergence in Europe (MacDonald and Taylor, 1991; Artis and Nachane, 1991; Hall, Robertson and Wickens, 1992; Ardeni, 1992; Caporale and Pittis, 1993; Loufir and Reichlin, 1993; Berk and Winder, 1994; and Camarero and Tamarit, 1996).

Although nominal convergence can be considered as a system where there are other nominal variables, this paper focuses only on the evolution of prices. The reason for this selection is that price differential is a key variable to measure the competitiveness gap in an adjustable peg system and then, the need for any eventual devaluation.

The data sample used in this paper covers the period 1980-1994 and refers to the price series of Italy, Spain, UK, Germany and a European aggregate. The series studied are the industrial output prices index and the consumer prices. Although only prices relating to tradeables should be used to assess price competitiveness, from an economic policy point of view, consumer prices are more relevant as the inflation rate targets of the monetary policy, and the "official" convergence criterion of the Maastricht Treaty are defined in terms of this index.

The econometric methodology comprises a range of techniques. These include the use of the Kalman filter to investigate the extent to which the process of convergence has altered over time as well a methodology used up to now in the context of Growth Theory and based on a framework testable by cointegration procedures. More specifically, some unit root tests allowing for structural breaks when the breakpoint is unknown (Zivot and Andrews, 1992 

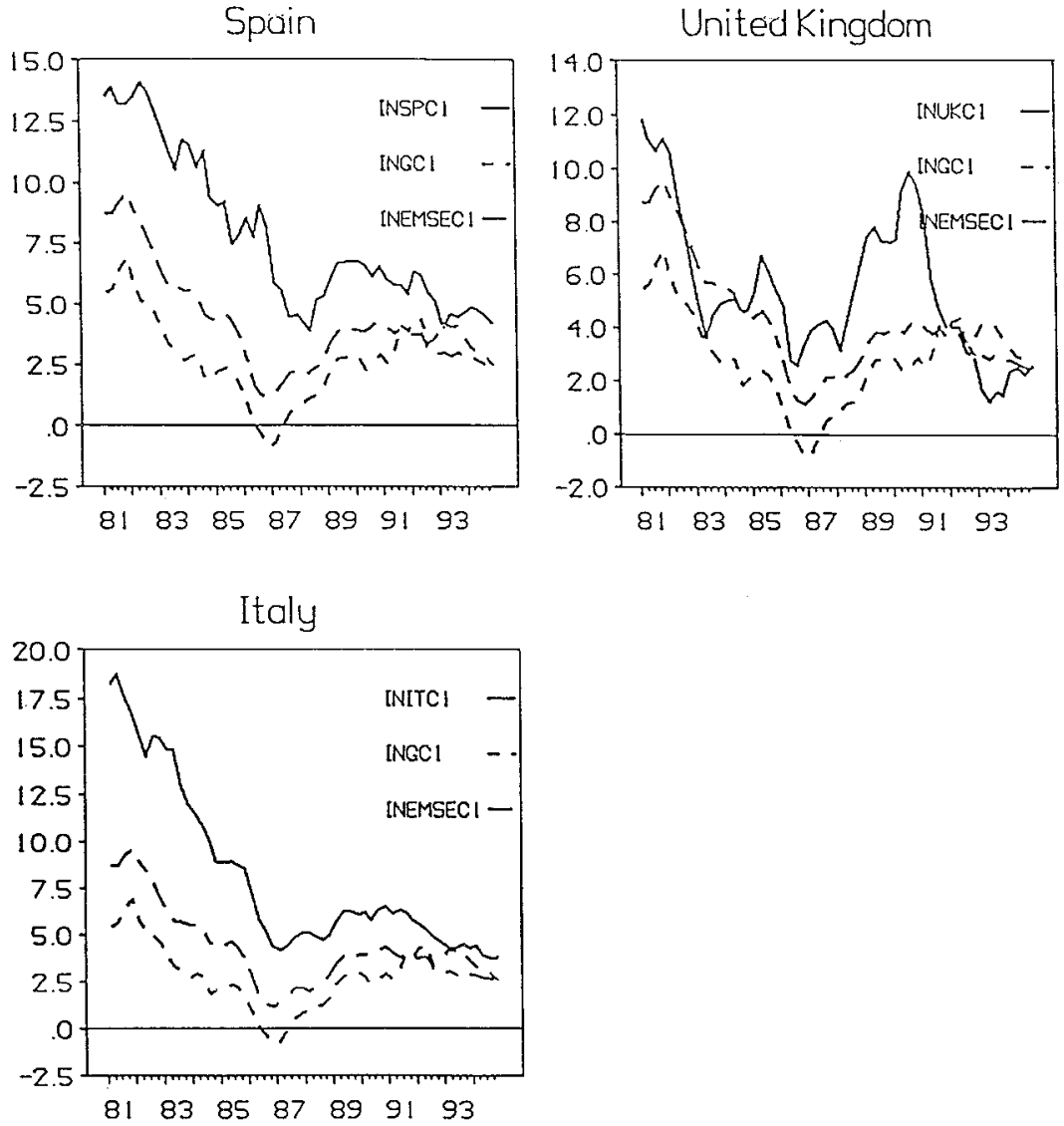

Fig. 1. CPI inflation rates of the peripheral countries compared to Germany and the EMS average

and Perron and Vogelsang, 1992a, 1992b and 1993a) have been used to asses the existence of convergence.

The rest of the paper is organized as follows. Section 2 discusses several ways of measuring convergence as well as the notion of convergence itself. Section 3 presents the different testing hypotheses coming from the stochastic properties of the inflation differentials. Section 4 presents the empirical results and, finally, section 5 concludes the paper.

\section{Defining convergence in the context of integrated time series}

Research in time series analysis has revealed that it is usually relevant to distinguish between stationary and non-stationary ${ }^{1}$ series. If a series is non-

\footnotetext{
${ }^{1}$ In this paper we use the term "non-stationary" to refer to the more accurate concepts of "integrated" or "time-homogeneous non-stationary" variables.
} 
Spain
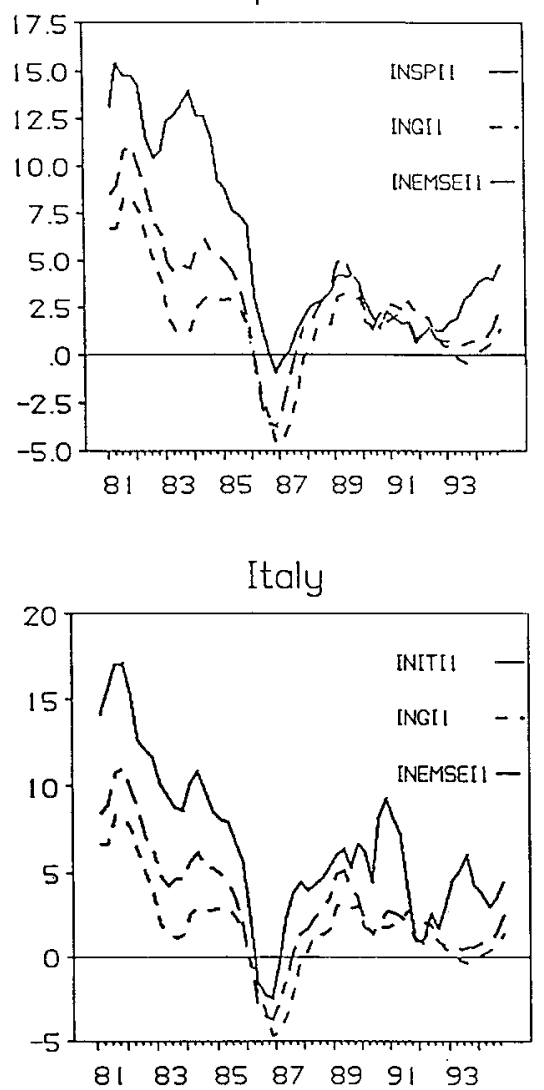

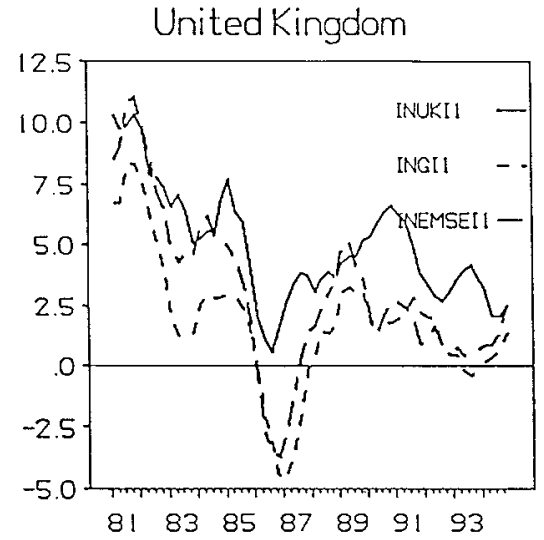

Fig. 2. Industrial output price inflation rates of the peripheral countries compared to Germany and the EMS average

stationary it has the potential for very large variation over time, so that for convergence to exist between two non-stationary series, cointegration must be a necessary, but not sufficient, condition. Only in this case the differences between the series do not have infinite variances. If the series under consideration are $I(1)$ it may be reasonable to define convergence in terms of the difference between them being a lower order of integration than the series under consideration (Hall, Robertson and Wickens, 1992).

Bernard and Durlauf (1995) define long-run convergence between countries $i$ and $j$ if the long-term forecasts of the considered variable for both countries are equal at fixed time $t$ :

$$
\lim _{k \rightarrow \infty} E\left(p_{i, t+k}-p_{j, t+k} \mid \xi_{t}\right)=0
$$

where $\xi_{t}$ stands for the information available at time $t$. This definition will be satisfied if $p_{i, t+k}-p_{j, t+k}$ is a mean zero stationary process. It implies that for countries $i$ and $j$ to converge the two series must be cointegrated with co- 
integrating vector $[1,-1]$. In addition, if the variables are trend-stationary, then the definitions imply that the time trends for each country must be the same.

All these conditions have been applied extensively to study the existence of nominal convergence with the main problem being that convergence is a gradual and on-going process. Testing for cointegration is a powerful way of assessing whether convergence has already occurred. However, if convergence is in process, any test which assumes structural stability will almost certainly be biased towards the rejection of convergence for the whole period. Therefore, a measure of convergence which allows for dynamic structural change is needed. Moreover, the notion of convergence behind the Maastricht Treaty is less restrictive than the concept of cointegration. The Treaty states that the countries must be in the process of convergence but that this process does not have to be achieved completely.

Recently, Bernard and Durlauf (1995, 1996), Oxley and Greasley (1995) and Greasley and Oxley (1997) have proposed different definitions or degrees of convergence (convergence, catching-up and common trends) yielding to an appropriate testing framework based on cointegration techniques. According to these authors the definition of convergence given above would correspond to the concept of long-run convergence. However, it could be the case that both series are not equal in the long-term, but proportional. That is, they may still respond to the same long-run driving processes and face the same permanent shocks with different long-run weights or different magnitude across countries. In this case the series would be cointegrated but the cointegrating vector would be $[1, \alpha]$ with $\alpha$ being $<0$ and both series would show a common trend.

Finally, if both series are cointegrated and the cointegrating vector is $[1,-1]$, but the difference between the two series is a stochastic variable with a non-zero time trend, this will show that the deviation between the series is expected to decrease but not to disappear. This case is called catching-up by Bernard and Durlauf $(1995,1996)$ and Oxley and Greasley $(1995)$.

The latest definition is the appropriate in our context as it has been stated that, at least for the peripheral countries, convergence is an on-going process. Now, the problem is how to test for the different degrees of convergence. These definitions of convergence given above are closely linked to the concepts of deterministic and stochastic cointegration ${ }^{2}$. A possible empirical strategy could be to test for unit roots in the difference between two individual series. The joint rejection of a unit root and a deterministic trend (deterministic cointegration) would imply the existence of convergence. Conversely, if a deterministic trend is present, that would mean that there is catching-up (stochastic cointegration).

However, the main problem related to the implementation of unit root tests in order to detect the presence of convergence is the possibility of structural discontinuities in the convergence process. In the empirical literature two methods have been implemented to solve this problem. First of all, testing for the possibility of structural breaks in the long-run relationships following the seminal works of Zivot and Andrews (1992) and Perron and Vogelsang (1992a, 1992b) in the field of the unit root tests. This approach has been

${ }^{2}$ For discussion about these concepts, see Park (1992). 
adopted by Carlino and Mills (1993) and Loewy and Papell (1996) using per capita income for the US regions and Greasley and Oxley (1997) for the European case. A second appealing way of solving this problem has been implemented by several authors using the time-varying parameters technique (Hall, Robertson and Wickens, 1992; Haldane and Pradham, 1992; and Loufir and Reichlin, 1993). The results of these studies show, in general, that EMS membership has contributed to the achievement of convergence in nominal variables. Consequently, real interest rate differentials have increased, and a loss of competitiveness has emerged in the most inflationary countries of the EMS.

In this paper, two tests for convergence are employed. The first one is based on the Kalman filter where the estimated bivariate relationships feature time varying parameters. This technique acknowledges that a closer convergence of EU inflation rates may have occurred during the ERM period through a number of structural changes. The second test of convergence is based on cointegration analysis and involves the examination of stochastic and deterministic trends in the residuals of the cointegrating relationships with structural breaks.

\section{Testing hypotheses}

\subsection{Time-varying parameters}

According to Hall, Robertson and Wickens (1997) the most appropriate way of assessing if a country has begun a process of convergence is the use of timevarying parameters models. This technique allows for a dynamic structural change in the implied variables and can also measure the speed of convergence.

From an economic point of view this will permit us to determine if a country has committed itself from a certain point of the sample considered into a process of price convergence in order to meet the criterion laid down in the Maastricht Treaty.

This paper follows the methodology proposed by Haldane and Hall (1991) and applied with some variations in Hall, Robertson and Wickens (1992, 1997) and Loufir and Reichlin (1993). According to these authors, equation (1) means that convergence in expectation in the time varying difference between two series occurs if the resulting process evolves into a stationary process. The stronger definition of convergence in probability will be satisfied if the time varying process evolves into a deterministic constant with zero variance. However, as these authors point out, this seems unlikely in the case of economic time series with measurement errors. In this paper we consider a minor modification to this approach that allows us to address a slightly different problem. Instead of testing whether a series is converging to a particular series we might be interested in testing whether it is converging to one of several alternative series. This can be accomplished by considering the following model:

$$
\pi_{G t}-\pi_{S t}=\alpha_{S t}+\beta_{S t}\left(\pi_{G t}-\pi_{\mathrm{EMS} t}\right)+u_{G t}
$$

where $\pi$ stands for the rate of inflation of any three countries (or index) $G, S$ 
and EMS, and:

$$
\begin{aligned}
& \alpha_{S t}=\alpha_{S t-1}+\varepsilon_{1 t} \\
& \beta_{S t}=\beta_{S t-1}+\varepsilon_{2 t} \\
& u_{G t} \sim N\left(O, \sigma^{2}\right) \\
& \varepsilon_{1 t} \sim N\left(O, \Omega_{1 t}\right) \\
& \varepsilon_{2 t} \sim N\left(O, \Omega_{2 t}\right) \\
& \Omega_{1 t}=\phi_{1} \Omega_{1 t-1} \\
& \Omega_{2 t}=\phi_{2} \Omega_{2 t-1} \\
& \Omega_{10} \Omega_{20} \quad \text { given, }
\end{aligned}
$$

In this framework, the evolution of $\alpha_{t}$ and $\beta_{t}$ will provide information about the achievement of convergence. If the $\pi_{G t}$ and $\pi_{S t}$ series have converged we would expect that $\beta \rightarrow 0$ and $\alpha \rightarrow 0$. Conversely, if $\pi_{S t}$ and $\pi_{\text {EMS }}$ have converged we would find that $\alpha \rightarrow 0$ and $\beta \rightarrow 1$. This condition fits the definition of weak convergence given above and so a formal measure of convergence is given directly by the trend in these two parameters. If we impose $\alpha=0$, the two feasible scenarios are:

a) $\beta \rightarrow 0 \Rightarrow \pi_{S t}=\pi_{G t}$

b) $\beta \rightarrow 1 \Rightarrow \pi_{S t}=\pi_{\mathrm{EMS} t}$;

If $\pi_{G t}<\pi_{\mathrm{EMS} t}$, this yields the following possible values for $\beta$ :

c) $0 \leq \beta \leq 1 \Rightarrow \pi_{G t}<\pi_{S t}<\pi_{\mathrm{EMS} t}$;

d) $\beta>1 \Rightarrow \pi_{G t}<\pi_{\mathrm{EMS} t}<\pi_{S t}$

e) $\beta<0 \Rightarrow \pi_{S t}<\pi_{G t}<\pi_{\mathrm{EMS} t}$

As in the above example, in this paper Germany and an aggregate variable representing the EMS have been chosen as reference variables. This last case is the relevant one in this study because during the sample period the German inflation rate has been lower than the one of the weighted European average.

The model that appears in equation (2) can be estimated using the Kalman filter $^{3}$. The likelihood function for this model, defined by $L\left(\phi, \Omega_{0}\right)$, can be constructed using the Kalman filter and estimates of the parameters can be obtained by a non-linear search algorithm. The graphic representation of the estimated time-varying coefficients for $\beta(t)$ allows us to assess the situation and the speed of country $S$ in the process of convergence. In this way we can also test whether a change of regime has occurred with the series of concern altering its behavior.

${ }^{3}$ A technical description of the estimation methodology may be found in Loufir and Reichlin (1993). 


\subsection{Cointegration framework}

Before starting this section a number of methodological caveats should be borne in mind. First, the time series plotted in figures $1-4$ are only conceivable as realizations from linear dynamic systems if they start from a pronounced disequilibrium. If this interpretation is adopted, however, statistics follow atypical distributions as they have not been sampled from the steady state but from a disequilibrium starting phase. This fact could rise some doubts on the reliability of the empirical findings. Secondly, as claimed by Bernard and Durlauf (1995) if the countries in our sample start at different initial conditions and are converging to, but are not yet at a steady-state, then the available data may be generated by a transitional law of motion rather than by an invariant stochastic process. Consequently, unit root tests may erroneously accept a no-convergence null. Finally, there is empirical evidence that shows the non linear and non stationarity nature of the inflation rates in different countries (Perron, 1993).

Bearing in mind all the above criticisms, we focus in the present study solely on the long-run properties of prices. These properties are characterized by the order of integration of the deviations of the neperian logarithms of prices $\left[\ln \left(P_{t}\right)\right]$ from their deterministic paths (Nelson and Plosser, 1982). In addition, the existence of a structural break over the period considered (1980Q1/1994-Q4) will be tested on both single variables.

Let us consider a price variable $P_{t}$ for which the following model is postulated:

$$
\ln \left(P_{t}\right)=\alpha_{0}+\alpha_{1} t r_{t}+\varepsilon_{t}
$$

where $t r$ is a deterministic trend variable, $t$ the time index, $\alpha_{0}$ and $\alpha_{1}$ constant parameters and $\varepsilon_{t}$ a disturbance term. If $\varepsilon_{t}$ follows a stationary process, the price variable is called trend-stationary, but if $\varepsilon_{t}$ is integrated of order $1, I(1)$, the price level is difference-stationary. In the former case, deviations from the deterministic growth path are only temporary. Hence, an error correction mechanism is present. In the latter case, this mechanism is absent, causing a shock to have a permanent effect on the future price level.

As the price convergence criterion in the Maastricht Treaty has been formulated in terms of inflation, equation (10) can be rewritten as follows:

$$
\Delta \ln \left(P_{t}\right)=\alpha_{1}+\Delta \varepsilon_{t}
$$

If the price variable is $I(1)$, a one-time disturbance will lead to a temporary deviation of the inflation rate from its equilibrium value, $\alpha_{1}$. However, if the price series is trend-stationary, the same initial deviation of the inflation rate will occur, but it will be followed in future periods by an adjustment with the opposite sign. Therefore, in both cases, the effect of a price shock on the inflation rate is only temporary.

Using the two expressions above, the difference between Spanish $(P S)$, and German prices $(P G)$, can be formulated as follows:

$$
\ln \left(P S_{t} / P G_{t}\right)=\alpha_{0}-\beta_{0}+\left(\alpha_{1}-\beta_{1}\right) t r_{t}+\varepsilon_{t}-\mu_{t}
$$


and, the inflation rate differential would result as:

$$
\Delta \ln \left(P S_{t}\right)-\Delta \ln \left(P G_{t}\right)=\alpha_{1}-\beta_{1}+\Delta\left(\varepsilon_{t}-\mu_{t}\right)
$$

If Purchasing Power Parity (PPP) holds, the two inflations rates must be equal to avoid changes in the exchange rate. Equation (13) shows that, provided that the order of integration of the price variables does not exceed 1 , the condition $\alpha_{1}=\beta_{1}$ is a necessary and sufficient condition. This restriction implies that the prices in both countries have the same trend behavior. Consequently, the inflation rates are identical if temporary divergences are ignored.

However, some positive inflation differential with Germany is expected for the European peripheral countries. This fact would imply that $\alpha_{1} \neq \beta_{1}$, and therefore that prices in both countries exhibit different trend behavior. Which are the consequences for equation (12)? If the slope coefficients $\alpha_{1}$ and $\beta_{1}$ differ, the ratio of the prices will display a deterministic trend. Therefore, even if cointegration occurs, a competitiveness gap will increase or decrease systematically between the two countries.

Therefore, in this paper, we test for a shift in the regime of economic policy, and particularly, in the behavior of Spanish price series, before and after the entry into the EU (and more precisely, into the ERM). At that time, the peg between the peseta and the Dmark began to be used as policy objective, and therefore, an individual perturbation which has a permanent effect on the future course of prices is expected. In the case of the UK the breakpoint could occur when the pound entered into the ERM. Finally, a change is expected for Italy after the Basle-Nyborg agreement.

In order to do so it is crucial, as mentioned in section 2, the distinction between different levels of convergence (catching-up and convergence). These levels of convergence are closely linked to the concepts of stochastic and deterministic cointegration, respectively ${ }^{4}$.

There is a process of catching-up between the price indexes of two countries (i.e. Spain and Germany), $P S_{t}$ and $P G_{t}$, when there is a narrowing of the gap signalling that the countries though catching-up had not yet converged. Formally, assuming two dates, $t$ and $t+T$, and two price indexes, $P S_{t}-$ $P G_{t}>0, \forall t$, the definition of catching-up is as follows:

$$
E\left(P S_{t+T}-P G_{t+T} \mid \xi_{t}\right)<P S_{t}-P G_{t}
$$

The concept of catching-up implies the absence of a unit root in the difference between the two time series. Hence a stochastic trend would violate the proposition although the occurrence of a deterministic trend would not, implying the existence of stochastic cointegration between both variables.

Conversely, long-run convergence is a more demanding level of convergence that can be formally defined as:

$$
\lim _{k \rightarrow \infty} E\left(P S_{t+k}-P G_{t+k} \mid \xi_{t}\right)=0
$$

Long-run convergence implies both the absence of a unit root and a time

${ }^{4}$ See Park (1992) and Oxley and Greasley (1995). 
trend in the deterministic process. In this case a sufficient condition for convergence would require both stochastic and deterministic cointegration between the two series.

\section{Empirical results: price and inflation convergence}

The empirical evidence found in this paper has shed some light on the debate over price and inflation convergence in the ERM. By examining a general and a manufacturing index separately, we are evaluating the behavior of predominantly traded and non-traded sectors. The discipline required to achieve inflation convergence may be obtained either through international trade in a regime of relatively fixed exchange rates and/or through increased financial integration which will affect both sectors. This study allows us to assess which effect is dominant. A priori, is seems plausible to argue that evidence of German leadership might be strongest in the case of manufactured goods which are relatively more tradable. Moreover, this study may provide an additional insight into the literature of Purchasing Power Parity (PPP). According to the relative version of PPP, increased mobility of goods and services and increased fixity of nominal exchange rates should have facilitated the achievement of relative PPP, particularly in manufacturing.

\subsection{Time-varying parameters models}

The results from this analysis applied to the case of the CPI and the IOP indexes appear in Figure 3. First, the case of Spain using consumer prices is displayed. The Figure shows that there has been a definite tendency for the slope coefficient to move towards one. This would signal a process of convergence to the European average, but not to Germany which is confirmed by the results of the next section. It is worth noting that the speed of convergence accelerated sharply after the Spanish entry into the EC in 1986 and that a second more moderate process of convergence began only after the Spanish membership in the ERM in 1989. Second, in the case of the industrial prices there has been a process of convergence to the German levels. Thus, the $\beta$ coefficient began a declining evolution from 1984, arriving to the zero level in 1988 in two stages: the first one would be in 1984-85, anticipating the Spanish membership in the EC and the second one during the transition period of tariff reduction (1986-88). This was a period when there were almost no realignments in the ERM and the system gained in credibility. The devaluations occurred after 1992 pushed the industrial output prices back to their level in $1987^{5}$.

The case of Italy appears at the bottom left panel of Figure 5 for both consumer and industrial output prices. It is noteworthy to recall the diversity of experiences with regard to the use of capital controls. Thus, while the UK abolished them in October 1979, and Germany had lifted all restrictions by 1981, France, Italy and Spain used exchange controls that have been grad-

\footnotetext{
${ }^{5}$ Speculative crises in the ERM in the early 1990's resulted in the exit of Italy and the UK from the ERM in September 1992 and the subsequent widening of the permitted bands of exchange rate fluctuation around a $15 \%$ for the remaining members.
} 

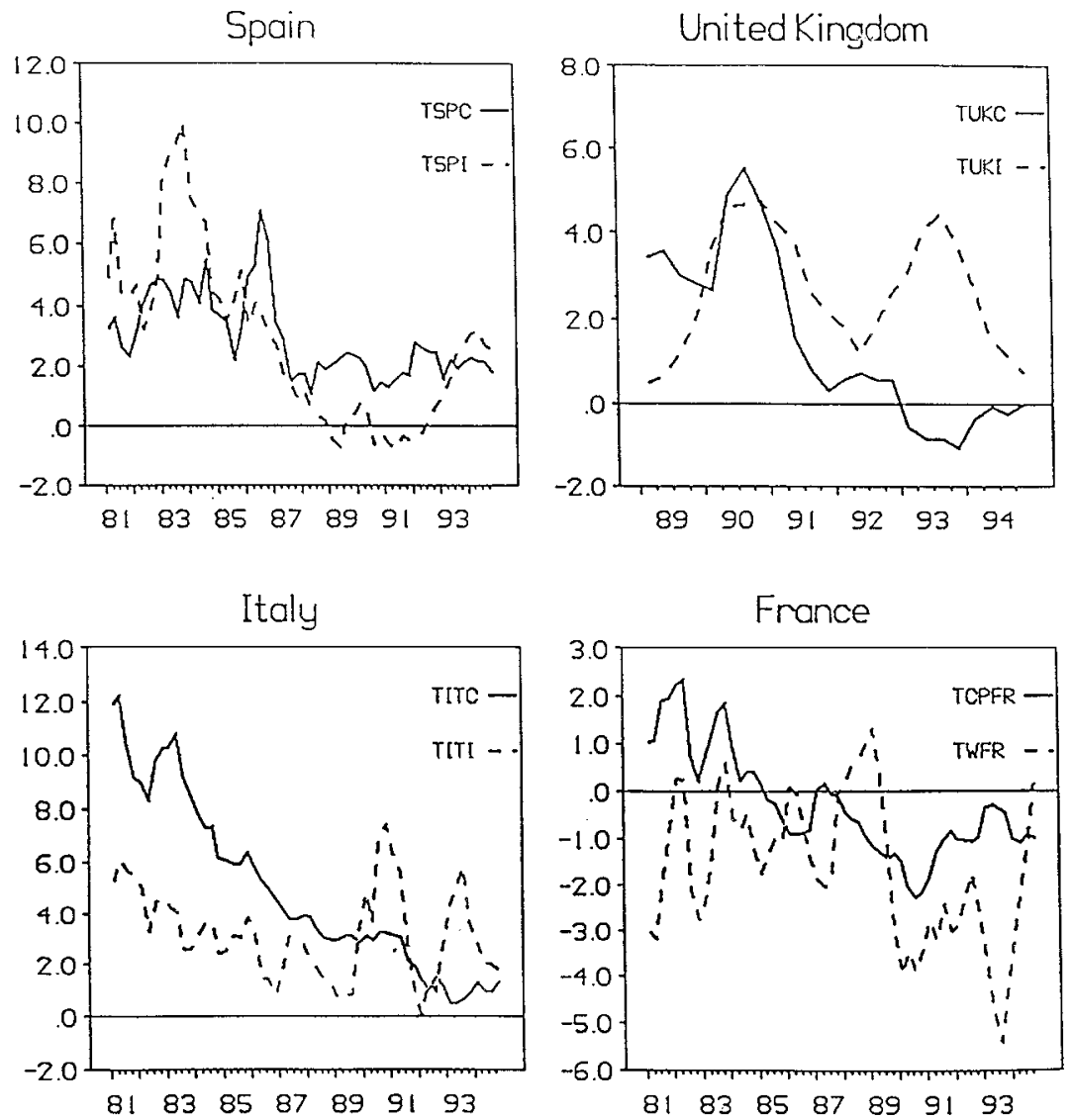

Fig. 3. CPI and industrial output price indexes inflation differentials: Germany vs. EMS time varying parameter: slope $(B)$

ually relaxed over the period of the ERM with the removal of all controls by 1990. It can be clearly seen that Italy was following a disinflationary process of convergence from the beginning of the sample. This result was expected as Italy is a founder member of the EMS. Thus, $\beta$ is decreasing along the period considered until 1992 when the process of convergence seems to stop around a value of 1 (the European average). As for the industrial output prices, there seems to be a process of convergence altered by the exchange rate devaluations after 1992 when Italy abandoned the EMS.

The evolution of $\beta$ for the UK shows that the "German leadership" hypothesis does not apply for this country along the period considered. Only when it takes place the entry of the pound into the ERM, there is a sharp decline in $\beta$ that stabilized around 0 (convergence with Germany) in 1992 when the UK abandoned the discipline of the EMS.

Finally, the case of France has been considered as a control country. As it is well known, after the problems suffered by the first socialist government a sharp change in the economic policy occurred. Hence, France committed itself to a process of disinflation using the exchange rate as the key tool, the so- 
called "franc fort" policy. As can be seen from the graph convergence with Germany was achieved around 1985-87. From that moment on $\beta$ has been negative, showing the better performance of the French inflation compared to the German one.

\subsection{Some further evidence: Trend behavior of prices with standard unit root tests}

As was previously stated, in order to get price convergence, trendlike behavior in both countries is needed. This condition is equivalent to saying that the price ratio between the two countries has to be a stationary variable (Berk and Winder, 1994).

The results from the unit root Phillips-Perron (P-P) tests and KPSS tests are reported in Table 1. These tests are applied to price series (consumer prices and industrial output prices) from Italy, Spain, UK, Germany and the EMS

Table 1. Unit root and stationarity tests ${ }^{\mathrm{a}}$ (1980: Q1-1994: Q4)

\begin{tabular}{|c|c|c|c|c|c|}
\hline \multirow[t]{2}{*}{ Variable } & \multicolumn{3}{|c|}{ Phillips-Perron Test ${ }^{\mathrm{b}}$} & \multicolumn{2}{|c|}{ KPSS Test $^{\mathrm{c}}(l=4)$} \\
\hline & $Z\left(t_{\tilde{\alpha}}\right)$ & $Z\left(t_{\alpha} *\right)$ & $Z\left(t_{\hat{\alpha}}\right)$ & $\eta_{\mu}$ & $\eta_{\tau}$ \\
\hline spratlc $_{t}$ & -2.28 & $-4.03 * *$ & $-5.51^{* *}$ & $1.25^{* *}$ & $0.32 * *$ \\
\hline spratli $i_{t}$ & -1.67 & $-3.68 *$ & $-4.97 * *$ & $1.06^{* *}$ & $0.31 * *$ \\
\hline sprat $2 \mathrm{c}_{t}$ & 0.08 & $-6.15^{* *}$ & $-6.96^{* *}$ & $1.24^{* *}$ & $0.32 * *$ \\
\hline sprat $2 i_{t}$ & -1.61 & $-4.04 * *$ & $-5.69^{* *}$ & $1.10^{* *}$ & $0.31 * *$ \\
\hline itratlc $_{t}$ & $-4.20 *$ & $-13.4^{* *}$ & $-8.82^{* *}$ & $1.21 * *$ & $0.31 * *$ \\
\hline itrat $1 \mathrm{i}_{t}$ & -2.91 & -2.21 & $-3.91^{* *}$ & $1.28 * *$ & $0.19 *$ \\
\hline itrat $2 c_{t}$ & $-3.71^{*}$ & $-15.4^{* *}$ & $-11.1 * *$ & $1.20 * *$ & $0.32 * *$ \\
\hline $\operatorname{itrat} 2 \mathrm{i}_{t}$ & -2.23 & $-3.55^{*}$ & $-5.07 * *$ & $1.26^{* *}$ & $0.28 * *$ \\
\hline $\mathrm{ukrat} \mathrm{c}_{t}$ & -1.44 & -0.90 & $-2.20^{*}$ & $1.17^{* *}$ & $0.18 *$ \\
\hline ukratli $i_{t}$ & -2.06 & 0.31 & -1.55 & $1.26^{* *}$ & $0.21 *$ \\
\hline ukrat $2 \mathrm{c}_{t}$ & -0.84 & -2.35 & $-4.44 * *$ & $1.26^{* *}$ & $0.16^{*}$ \\
\hline ukrat $2 i_{t}$ & -1.67 & -1.27 & $-3.33^{* *}$ & $1.29 * *$ & $0.21 *$ \\
\hline
\end{tabular}

\section{Notes:}

a $* y * *$ denote significance at the $5 \%$ and $1 \%$ levels, respectively.

b The tests statistics $Z\left(t_{\tilde{\alpha}}\right), Z\left(t_{\alpha} *\right)$ and $Z\left(t_{\hat{\alpha}}\right)$ are the non-parametric corrections of Phillips and Perron (1988) applied, respectively, to the tests $\hat{\tau}_{\tau}, \hat{\tau}_{\mu}$ and $\hat{\tau}$ in the terminology of Fuller (1976).

c The Phillips and Perron (1988) test has been calculated using the long-run variance estimator as proposed in Andrews (1991) and Andrews y Monahan (1992). The critical values are taken from Fuller (1976), table 8.5.2.c.

d The long-run variance has been estimated using the procedure proposed in Newey and West (1987). The critical values for $\eta_{\tau}$ and $\eta_{\mu}$, which correspond to the test statistics with and without trend, respectively, are taken from Kwiatkowski et al. (1992).

Critical values:

\begin{tabular}{llllll} 
& $5 \%:$ & $1 \%:$ & & $5 \%$ & $1 \%$ \\
$Z\left(t_{\tilde{\alpha}}\right):$ & -3.60 & -4.38 & $\eta_{\mu}:$ & 0.463 & 0.739 \\
$Z\left(t_{\alpha} *\right):$ & -3.00 & -3.75 & $\eta_{\tau}:$ & 0.146 & 0.216 \\
$Z\left(t_{\hat{\alpha}}\right):$ & -1.95 & -2.66 & & & \\
\hline
\end{tabular}


and its differentials ${ }^{6}$. As almost all of the countries considered followed a disinflationary policy during the 80 's, we expect that the price series present a deterministic trend. In this case, the relevant statistics are the ones presented in the first column for the P-P test and the second column for the KPSS test. Both tests allow us to consider the series as $I(1)$ processes. The conclusion might therefore be that European peripheral countries and German prices (or European peripheral countries and EMS aggregate prices) are not cointegrated and that shocks have a permanent effect on the relative price ratio between the two countries. This result would lead us to conclude the rejection of the long-run convergence hypothesis for all the European peripheral countries. However, in these cases, a reduction of the gap between the pairs of variables considered is expected in the form of a break in the deterministic trend function. Perron (1989) proved that a single shock may be responsible for this finding. Standard procedures cannot discriminate between situations in which each individual price shock has a permanent influence (i.e. the variable follows a random walk with drift) and situations in which only one important perturbation has a permanent effect (i.e. the variable is stationary around a trend which deterministic part is non-linear). This distinction will be implemented in the next section.

\subsection{Convergence and structural change}

Perron $(1989,1990)$ suggested that the above mentioned evidence might be due to the presence of important structural changes in the trend function. His approach consists of testing for a unit root allowing for the possibility of a one-time structural change in the trend function. He considers three kinds of changes or cases: a change in the intercept (case 1), a change in slope (case 3), or both (case 2).

Other authors have extended this line of research developing testing procedures when the breakpoint is not known [Zivot and Andrews (1992), Banerjee, Lumsdaine and Stock (1992), Perron (1990) and Perron and Vogelsang (1992a)].

The procedure is based on simple autoregressions (estimated by OLS) appropriately augmented with trend and dummy components. The test statistics are based on the values of the $t$-statistics for testing that the sum of the autoregressive coefficients is equal to one.

Two approaches, and two kinds of models, are considered. The first one, called the "Innovational Outlier" (IO) approach models the break as occurring slowly over time and feeding back into the process dynamics, as opposed to the second one, the "Additive Outlier" (AO) approach, where the change is assumed to occur instantly and has no further effects on future observations.

Models 1 and 2 can be nested, and the unit root hypothesis tested in the following Dickey-Fuller (1979) type regressions estimated by OLS:

Case 1: Change in the intercept.

$$
y_{t}=\mu+\beta t+d D\left(T_{b}\right)_{t}+\theta D U_{t}+\alpha y_{t-1}+\sum_{i=1}^{k} c_{i} \Delta y_{t-i}+u_{t}
$$

\footnotetext{
${ }^{6}$ The results for the individual series indicate that all of them are $I(1)$. These results are not reported in Table 1 for the sake of simplicity but are available from the authors upon request.
} 
Case 2: Change in the intercept and the slope.

$$
y_{t}=\mu+\beta t+d D\left(T_{b}\right)_{t}+\theta D U_{t}+\gamma D T_{t}+\alpha y_{t-1}+\sum_{i=1}^{k} c_{i} \Delta y_{t-i}+u_{t}
$$

Case 3: Change in the slope.

$$
y_{t}=\mu+\beta t+\gamma D T_{t}+\alpha y_{t-1}+\sum_{i=1}^{k} c_{i} \Delta y_{t-i}+u_{t}
$$

where $y$ is the variable of interest; $d D\left(T_{b}\right)=1$ if $t=T_{b}, 0$ otherwise; $D U=1$ if $t>T_{b}, 0$ otherwise; $D T=t-T_{b}$, and $D T=t$ if $t>T_{b}$ and 0 otherwise, and $T_{b}$ refers to the time of the break.

Under the null hypothesis of a unit root, $\alpha=1$ and $\theta=0$ in cases 1 and 2, and $\gamma=0$ in cases 2 and 3. In case 3, a break in the trend is not permitted under the null. The null hypothesis is tested using the $t$-statistic for testing $\alpha=1$ in the three regressions. Therefore cases 1 and 2 can be tested using additive or innovational models. However, case 3 is only compatible with the additive model.

Simple graphic inspection of the data provides information with respect to the possibility that a structural change has occurred, and if so when it has taken place. Hence, Figure 4 shows the evolution of the CPI ratios (logarith-
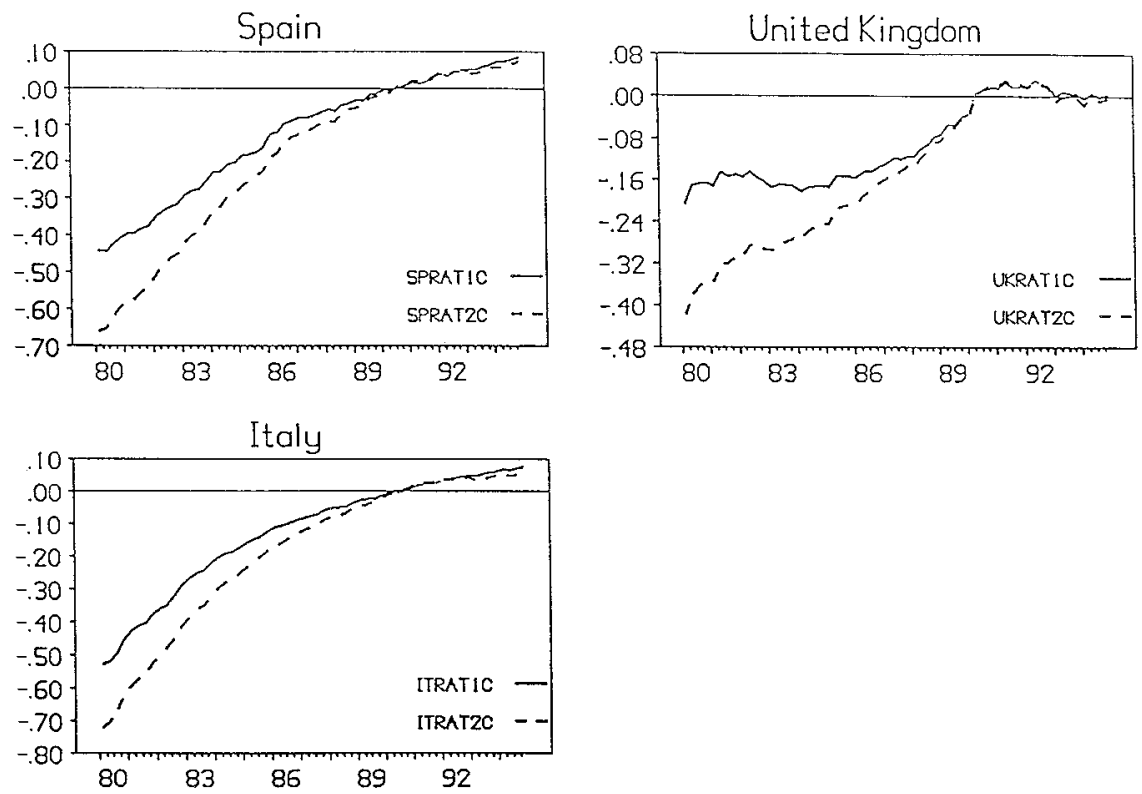

Fig. 4. CPI ratios of the peripheral countries

1: EMS average

2: Germany 

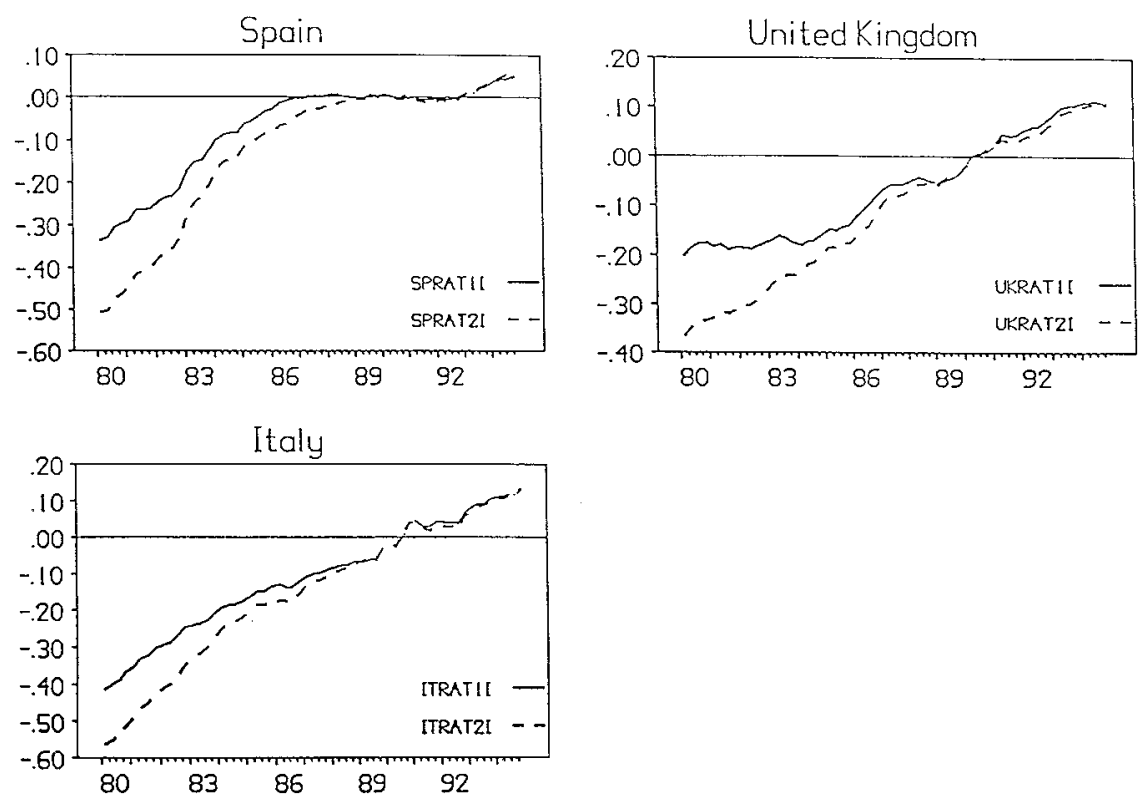

Fig. 5. Industrial output price indexes ratios of the peripheral countries 1: EMS average

2: Germany

mically transformed) between the European peripheral countries and the EMS and these countries and Germany. In Figure 5 the same is depicted for the case of the industrial output prices.

During the first part of the sample period all of the series show a strong increase. This fact reflects that European peripheral countries prices systematically rose faster than in the other European countries. However, in the middle of the 80 's a breakpoint in the trend occurred. This performance was due either to the entry into the EC (Spain), the ERM (UK) or the BasleNyborg agreement (Italy).

Concerning the industrial output prices a special feature has to be pointed out. In the case of Spain from the breakpoint on, the ratio is nearly constant and almost zero. The different performance of the two price indexes may be due to their different structure; industrial output prices are a weighted average of tradeable goods and therefore all of them are bought and sold in competitive markets. This is not the case of the services, which are an important part of the CPI.

The industrial output price ratio's stability around zero means that the inflation differential in tradeable goods between Spain and Germany (or the ERM) is almost null. However, there is a change in this behavior since 1992 when several devaluations occurred. These devaluations were used by the entrepreneurs to rise their mark-up, and consequently caused an increase of the industrial output prices index.

In this paper the changes of the price series seem to be instantaneous and, as a consequence, an Additive Outlier Model (AOM) has been estimated for cases 2 and 3. In the former a change in the intercept is followed by a different 
Table 2. Unit root tests allowing for structural breaks (Ratios) Quarterly data (1980-Q1 1994-Q4)

\begin{tabular}{|c|c|c|c|c|c|c|c|c|}
\hline Series & Model & $T_{b}$ & $k$ & $\hat{\beta}$ & $\hat{\theta}$ & $\hat{\gamma}$ & $\hat{\alpha}$ & $\hat{t}_{\alpha}$ \\
\hline \multicolumn{9}{|c|}{ Selection criterion: $t$-sig $(\operatorname{Kmax}=5)$} \\
\hline spratlc $_{t}$ & $2-g$ & 85-Q3 & 4 & $\begin{array}{c}0.006 \\
(5.24)\end{array}$ & $\begin{array}{c}0.10 \\
(5.40)\end{array}$ & $\begin{array}{l}-0.004 \\
(-5.16)\end{array}$ & 0.52 & $-5.54^{* *}$ \\
\hline sprat $1 i_{t}$ & 3 & $85-\mathrm{Q} 4$ & 4 & $\begin{array}{l}0.014 \\
(50.9)\end{array}$ & & $\begin{array}{l}-0.013 \\
(-32.5)\end{array}$ & 0.44 & $-4.03^{*}$ \\
\hline sprat2 $c_{t}$ & $2-g$ & 85-Q3 & 0 & $\begin{array}{c}0.003 \\
(3.34)\end{array}$ & $\begin{array}{c}0.075 \\
(3.70)\end{array}$ & $\begin{array}{l}-0.002 \\
(-3.71)\end{array}$ & 0.80 & -3.57 \\
\hline sprat $2 i_{t}$ & 3 & $85-\mathrm{Q} 4$ & 4 & $\begin{array}{r}0.020 \\
(56.30)\end{array}$ & & $\begin{array}{c}-0.017 \\
(-34.2)\end{array}$ & 0.66 & $-4.31^{*}$ \\
\hline itrat $1 \mathrm{c}_{t}$ & 3 & 81-Q2 & 4 & $\begin{array}{r}0.049 \\
(8.24)\end{array}$ & & $\begin{array}{c}-0.040 \\
(-6.68)\end{array}$ & 0.92 & -3.33 \\
\hline itrat $1 i_{t}$ & $2-i$ & 89-Q2 & 4 & $\begin{array}{c}0.006 \\
(16.94)\end{array}$ & $\begin{array}{c}-0.05 \\
(-2.44)\end{array}$ & $\begin{array}{r}0.001 \\
(3.12)\end{array}$ & 0.35 & $-6.21^{* *}$ \\
\hline itrat $2 \mathrm{c}_{t}$ & 3 & 87-Q3 & 4 & $\begin{array}{c}0.02 \\
(50.55)\end{array}$ & & $\begin{array}{r}-0.015 \\
(-21.80)\end{array}$ & 0.90 & -3.03 \\
\hline itrat $2 i_{t}$ & $2-i$ & 89-Q3 & 4 & $\begin{array}{l}0.008 \\
(23.1)\end{array}$ & $\begin{array}{c}0.068 \\
(2.77)\end{array}$ & $\begin{array}{c}-0.001 \\
(-2.37)\end{array}$ & 0.14 & $-5.86^{* *}$ \\
\hline ukrat1c $c_{t}$ & $2-g$ & 89-Q4 & 4 & $\begin{array}{c}0.003 \\
(5.48)\end{array}$ & $\begin{array}{c}0.18 \\
(5.31)\end{array}$ & $\begin{array}{l}-0.003 \\
(-5.14)\end{array}$ & 0.53 & $-5.64^{* *}$ \\
\hline ukratli $i_{t}$ & $2-i$ & 87-Q1 & 4 & $\begin{array}{r}0.009 \\
(10.08)\end{array}$ & $\begin{array}{c}0.055 \\
(2.35)\end{array}$ & $\begin{array}{l}-0.002 \\
(-2.36)\end{array}$ & 0.54 & -4.16 \\
\hline ukrat $2 \mathrm{c}_{t}$ & $2-g$ & 89-Q4 & 4 & $\begin{array}{c}0.005 \\
(6.74)\end{array}$ & $\begin{array}{c}0.28 \\
(6.71)\end{array}$ & $\begin{array}{l}-0.006 \\
(-6.67)\end{array}$ & 0.47 & $-7.11^{* *}$ \\
\hline ukrat $2 \mathrm{i}_{t}$ & $2-i$ & 87-Q2 & 4 & $\begin{array}{r}0.010 \\
(19.30)\end{array}$ & $\begin{array}{c}0.11 \\
(7.52)\end{array}$ & $\begin{array}{l}-0.003 \\
(-6.46)\end{array}$ & 0.03 & $-6.00^{* *}$ \\
\hline
\end{tabular}

Notes: The $t$-statistics are in parentheses. The symbols * and ** represent significance of the test for $\alpha=1$ at $10 \%$ and $5 \%$ respectively, according to the critical values in Perron (1994), model 3: table 3A (10\%: -4.07, 5\%: -4.36), Vogelsang and Perron (1998), model $2-i$ : table 2, Panel (a) $(10 \%:-4.82,5 \%:-5.08)$ and the critical values in Perron (1994), model $2-g$ : table 2 .A $(10 \%$ : $-4.82,5 \%:-5.08)$.

growth path in the series, while in model 3 only a change in the growth rate occurs.

Next, the test by Vogelsang and Perron (1998) and Perron (1997), which allows us to test for important structural changes in the trend function when the breakpoint is unknown, is applied to the twelve ratios. The results appearing in Table 2 show that only when the ratio (for the two types of prices)

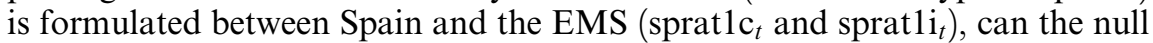
hypothesis of unit root be rejected. Hence, both series are stationary with a structural change. The breakpoint for both the consumer and the industrial output price indexes appears to occur at the end of 1985, just before the date of entry into the EC. This is also the case for the industrial output price ratio between Spain and Germany $\left(\right.$ sprat $2 \mathrm{i}_{t}$ ). However, it cannot be rejected that the consumer price ratio between Spain and Germany (sprat $2 \mathrm{i}_{t}$ ) is a difference stationary variable.

The former results can be interpreted in the following way. There is positive evidence of the fact that both consumer and industrial Spanish prices display a catching-up behavior to the EMS prices. However, the result is different when Germany is considered. In this case, there is only catching-up in the case of the industrial output prices. From an economic point of view, this 
performance means that there is a competitiveness gap that the "hard currency" policy implemented in Spain has failed to eliminate. When consumer prices are considered the results show that the ratio is not a stationary variable, which implies that the difference between the two variables does not have a bounded variance and therefore there is not evidence of convergence.

As for Italy, there is only evidence of catching-up for the case of the industrial output prices (itrat $1 \mathrm{i}_{t}$ and itrat $2 \mathrm{i}_{t}$ ) but not when consumer prices are considered (itrat $1 \mathrm{c}_{t}$ and itrat $2 \mathrm{c}_{t}$ ).

Finally, in the case of the UK the results display a process of catching-up with both the European average and Germany in terms of consumer prices (ukrat $1 \mathrm{c}_{t}$ and ukrat $2 \mathrm{c}_{t}$ ) but only with Germany in terms of industrial output prices $\left(u k r a t 2 i_{t}\right)$. The breakpoint for the consumer price ratios is in both cases the last quarter of 1989 , just some months before the entry of the pound into the ERM.

\section{Concluding remarks}

This paper investigates convergence between some European peripheral countries and German prices (or an EMS aggregate) during the period 1980Q1/1994-Q4. If in the long-run both countries' inflation rates are equal and the prices are cointegrated, the competitiveness between the two countries remains constant. However, as the process of convergence (in case it is taking place) is not expected to have finished yet, a less restrictive definition of convergence has been used and tested implementing two approaches: Kalman filter estimates and cointegration techniques. Although the results found using both methodologies are compatible, the drawbacks inherent to the use of unit root tests applied to non linear processes lead us to prefer the time varying parameter formulation as the most appropriate.

In this context, catching-up (or weak convergence) relates to the tendency for the inflation differential to narrow over time. Moreover, the results allow us to discriminate between the different speeds of convergence.

The empirical results show that Spain has followed a process of catchingup with the EMS aggregate both in terms of consumer prices and industrial output prices since its entry into de EC but only in industrial output prices with Germany. Italy only has followed a process of catching-up in terms of industrial prices, and finally, the UK has followed a process of catching-up with Germany that started in 1990 with the entry of the pound into the ERM.

To sum up, there exists evidence of catching-up but not of long-run convergence between prices of the peripheral and core countries in the EU. It is also evident that countries like France which continously participated in the ERM bands show a dramatically higher convergence rate than the late comers. These results are also valid when taking into account solely the manufactured sector. All these facts suggest some fears about the future developments of EMU despite the positive evolution performed by countries like Spain or Italy.

\section{Appendix 1: Data definitions and sources}

The data used in the analysis are taken from the International Financial Statistics of the IMF, unless otherwise specified. The data include the quarterly 
consumer price index and the industrial output price index. The sample period covers from 1980-Q1 to 1994-Q4. The series are in neperian logarithms.

lcpiemse ${ }_{t}$ : EMS consumer price index as an idiosincratic average for Spain weighted (in the ECU) of the countries taking part of the exchange rate mechanism (ERM*). Source: Camarero (1993).

$\operatorname{cpisp}_{t}$ : Spanish consumer price index.

cpig $_{t}$ : German consumer price index.

lipiemse ${ }_{t}$ EMS industrial output prices index as an idiosincratic average for Spain weighted (in the ECU) of the countries taking part of the ERM. Source: Camarero (1993).

ipisp : $\quad$ Spanish industrial output prices index.

$\operatorname{ipig}_{t}$ : $\quad$ German industrial output prices index.

cpii ${ }_{t}: \quad$ Italian consumer prices index.

ipii ${ }_{t}$ : Italian industrial output index.

cpiuk $_{t}$ : UK consumer prices index.

ipiuk $_{t}$ : UK industrial output index.

lcpiemsi ${ }_{t}$ : EMS consumer price index as an idiosincratic average for Italy weighted (in the ECU) of the countries taking part of the exchange rate mechanism (ERM*). Source: Camarero (1993).

lipiemsi $i_{t}$ EMS industrial output prices index as an idiosincratic average for Italy weighted (in the ECU) of the countries taking part of the ERM. Source: Camarero (1993).

lcpiemsu $_{t}$ : EMS consumer price index as an idiosincratic average for U.K. weighted (in the ECU) of the countries taking part of the exchange rate mechanism (ERM*). Source: Camarero (1993).

lipiemsu $u_{t}$ : EMS industrial output prices index as an idiosincratic average for U.K. weighted (in the ECU) of the countries taking part of the ERM. Source: Camarero (1993).

sprat1c $_{t}$ : Ratio between cpisp and lcpiemse $_{t}$.

sprat2c $_{t}$ : Ratio between cpisp $_{t}$ and $\operatorname{cpig}_{t}$.

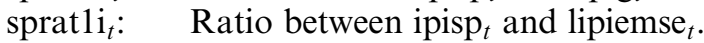

sprat $2 \mathrm{i}_{t}$ : $\quad$ Ratio between $\operatorname{ipisp}_{t}$ and $\operatorname{ipig}_{t}$.

itrat $1 \mathrm{c}_{t}$ : Ratio between cpii and $_{t}$ lcpiemsi $i_{t}$.

itrat $2 \mathrm{c}_{t}$ : $\quad$ Ratio between cpii $_{t}$ and $\operatorname{cpig}_{t}$.

itrat $1 \mathrm{i}_{t}$ : Ratio between $\mathrm{ipii}_{t}$ and lipiemsi $i_{t}$.

itrat $2 \mathrm{i}_{t}$ : $\quad$ Ratio between $\mathrm{ipii}_{t}$ and $\operatorname{ipig}_{t}$.

ukratlc $c_{t}$ : Ratio between cpiuk $_{t}$ and lcpiemsu . $_{t}$

ukrat2c $c_{t}$ : Ratio between cpiuk $_{t}$ and cpig $_{t}$.

ukratli $\mathrm{i}_{t}$ : Ratio between ipiuk and lipiemsu $_{t}$.

ukrat2i $\mathrm{i}_{t}$ : Ratio between ipiuk $_{t}$ and $\operatorname{ipig}_{t}$.

\section{References}

Andrews DWK (1991) Heteroskedasticity and autocorrelation consistent covariance matrix estimation. Econometrica 59:817-858

Andrews DWK, Monahan JC (1992) An improved heteroskedasticity and autocorrelation consisten covariance matrix estimator. Econometrica 60:953-966

* Germany, France, Belgium, Holland, Italy, Denkmark and Ireland. 
Ardeni PG (1992) On the way to the EMU: Testing convergence of the European economies. Economic Notes del Monte dei Paschi di Siena 21:238-257

Artis MJ, Nachane D (1991) Wages and prices in Europe: A test of the German leadership thesis. Weltwirtschaftliches Archiv 129:59-77

Banerjee A, Lumsdaine RL, Stock JH (1992) Recursive and sequencial tests of the unit root and trend break hypothesis. Journal of Business and Economic Statistics 10:271-287

Berk JM, Winder CCA (1994) Price movements in the Netherlands and Germany and the Guilder-DMark Peg. De Economist 142:63-74

Bernard AB, Durlauf SN (1995) Convergence in international output. Journal of Applied Econometrics 10:97-108

Bernard AB, Durlauf SN (1996) Interpreting tests of convergence hypothesis. Journal of Econometrics $71: 161-173$

Camarero M (1993) Un análisis empírico de los modelos monetarios de tipo de cambio con variables europeas agregadas. Ph.D. dissertation, University of Valencia

Camarero M, Tamarit CR (1996) Cointegration and the PPP anf the UIP hypotheses: An application to the Spanish integration in the EC. Open Economies Review 7:61-76

Caporale GM, Pittis N (1993) Common stochastic trends and inflation convergence in the EMS. Welwirtschaftliches Archiv 129:207-215

Carlino GA, Mills LO (1993) Are U.S. regional incomes converging? A time series analysis. Journal of Monetary Economics 32:335-346

Dickey DA, Fuller WA (1979) Distribution of the estimators for autoregressive time series with a unit root. Journal of the American Statistical Association 74:427-431

Fuller WA (1976) Introduction to statistical time series. Wiley, New York

Greasley D, Oxley L (1997) Time-series based tests of the convergence hypothesis: Some positive results. Economics Letters 56:143-147

Haldane AG, Hall SG (1991) Sterling's relationship with the dollar and the Deutschemark: 197689. The Economic Journal 101:436-443

Haldane AG, Pradhan M (1992) Real interest parity, dynamic convergence and the European monetary system. Working Paper Series No. 1, Bank of England

Hall SG, Robertson D, Wickens MR (1992) Measuring convergence of the EC economies. Papers in Money, Macroeconomics and Finance. Supplement Manchester School LX:99-111

Hall SG, Robertson D, Wickens MR (1997) Measuring economic convergence. International Jounal of Financial Economics 2:131-143

IMF (International Monetary Fund) Various issues. International Financial Statistics, Washington, D.C.

Kwiatkowski D, Phillips PCB, Schmidt P, Shin Y (1992) Testing the null of stationary against the alternative of a unit root. Journal of Econometrics 54:159-178

Leybourne SJ, Mills TC, Newbold P (1998) Spurious rejections by Dickey-Fuller tests in the presence of a break under the null. Journal of Econometrics 87:191-203

Loewy MB, Papell DH (1996) Are U.S. regional incomes converging? Some further evidence. Journal of Monetary Economics 38:587-598

Loufir R, Reichlin L (1993) Convergences nominale et réelle parmi les pays de la CE et de l'AELE. Observations et Diagnostiques Economiques No. 43:69-92

Macdonald R, Taylor MP (1991) Exchange rates, policy convergence, and the European monetary system. The Review of Economics and Statistics 73:553-558

Nelson CR, Plosser CI (1982) Trends and random walks in macroeconomic time series. Journal of Monetary Economics 10:139-162

Newey WK, West KD (1987) A simple, positive semi-definite heteroskedasticity and autocorrelation consistent covariance matrix. Econometrica 55:703-708

Oxley L, Greasley D (1995) A time-series perspective on convergence: Australia, UK and USA since 1870. The Economic Record 71:259-270

Park JK (1992) Canonical cointegration regressions. Econometrica 60:119-143

Perron P (1989) The great crash, the oil price shock and the unit root hypothesis. Econometrica 57:1346-1401

Perron P (1990) Testing for a unit root in a time series with a changing mean. Journal of Business and Economic Statistics 8:153-162

Perron P (1994) Non-stationnarités et non-linéarités dans le processus d'inflation au Canada in Banque de Canada (ed.), Comportement des agents économiques et formulation des 
politiques en régime de stabilité des prix. Actes d'un colloque tenu à la Banque de Canada en octobre 1993

Perron P (1997) Further evidence on breaking trend functions in macroeconomic variables. Journal of Econometrics 80:355-385

Perron P, Vogelsang TJ (1992a) Nonstationary and level shifts with an application to purchasing power parity. Journal of Business and Economic Statistics 10:301-320

Perron P, Vogelsang TJ (1992b) Testing for a unit root in a time series with a changing mean: Corrections and extensions. Journal of Business and Economic Statistics 10:467-470

Perron P, Vogelsang TJ (1993a) A note on the asymptotic distributions of unit roots tests in the additive outlier model with breaks. Revista de Econometría 13:181-201

Phillips PCB, Perron P (1988) Testing for a unit root in time series regression. Biometrica 75:335346

Vogelsang TJ, Perron P (1998) Additional tests for a unit root allowing for a break in the trend function at an unknown time. International Economic Review 39:1073-1100

Zivot E, Andrews DWK (1992) Further evidence on the great crash, the oil-price shock, and the unit-root hypothesis. Journal of Business and Economic Statistics 10:251-270 